\title{
Techniques: Shockwave lithotripsy may not be a good option in patients with previous renal superselective embolization
}

\author{
Jafar Hussaen; Sero Andonian, MD, MSc, FRCS(C), FACS
}

Division of Urology, Department of Surgery, McGill University Health Centre, Montreal, QC, Canada

Cite as: Can Urol Assoc J 2017;11 (9):E388-9. http://dx.doi.org/10.5489/cuaj.4453

Published online September 12, 2017

\section{Case and discussion}

A 53-year-old male, presented with a 20-year history of recurrent left nephrolithiasis. His past medical history was notable for vitamin B12 deficiency leading to mild thrombocytopenia (baseline platelet count of $\sim 70-100 \times 10^{9} / \mathrm{L}$ ) and polycythemia secondary to smoking. He was not on any anticoagulants or anti-platelet agents. He had two previous ureteroscopic laser lithotripsies for distal ureteral stones and extracorporeal shockwave lithotripsy (SWL) for an upper pole stone. He presented with a new left lower pole partial staghorn stone of $2.4 \times 1.2 \times 1.0 \mathrm{~cm}$ (HU 736) and underwent left tubeless percutaneous nephrolithotomy (Figs. 1 A, B). On postoperative Day 1, he developed persistent hematuria and his hemoglobin dropped from $185 \mathrm{~g} / \mathrm{L}$ to $144 \mathrm{~g} / \mathrm{L}$ with a platelet count of $117 \times 10^{9}$. He required super-selective angioembolization for a thrombosed pseudoaneurysm in a subsegmental lower pole branch. ${ }^{1}$ Eight months later, he presented with left flank pain. Repeat imaging showed recurrence of a $10 \times 6 \mathrm{~mm}$ stone in the left lower pole (Fig. $1 \mathrm{C}$ ). The patient was referred for left-sided SWL. His pre-SWL platelet count was $90 \times 10^{9} / \mathrm{L} .^{2}$ His pre- and intra-SWL blood pressure remained under 130/90 $\mathrm{mmHg}{ }^{3}$ The stone was fragmented under fluoroscopic guidance using a Storz Medical Modulith SLX lithotripter (Karl Storz, Tuttlingen, Germany). Three thousand shockwaves were delivered with a dose escalation up to a maximum energy level of 5. Postoperatively, he returned to the emergency room with severe left flank pain. He was tachycardic and his hemoglobin dropped from $166 \mathrm{~g} / \mathrm{L}$ to $83 \mathrm{~g} / \mathrm{L}$ over 48 hours, with a platelet count of $141 \times 10^{9}$. A computed tomography (CT) scan confirmed a perirenal hematoma of $5.4 \mathrm{~cm}$ (Fig. 1D). He underwent left renal arteriography and required super-selective embolization of the bleeding lower pole subsegmental vessel, which was different from the previously embolized vessel.
Despite its non-invasive nature, SWL is associated with clinically significant perirenal hematomas in $<1 \%$. Risk factors include uncontrolled hypertension, increasing age, body mass index, diabetes mellitus, atherosclerosis, and the number/frequency/intensity of shockwaves. ${ }^{3,4}$ The embolization coil within the lower pole of the kidney may have contributed to his peri-renal hematoma. Since the coil from the first embolization was in close proximity to the stone targeted during SWL, the embolization coil was within the path of the shockwaves, which could have caused the coil to migrate or cause damage to adjacent vessels via shear stress. ${ }^{5} \mathrm{We}$ believe that this was the mechanism that caused the perirenal hematoma post-SWL in this patient. Therefore, patients with previous embolization coils requiring lithotripsy could be managed with other minimally invasive approaches, such as ureteroscopic laser lithotripsy.

Competing interests: The authors report no competing personal or financial interests.

This paper has been peer-reviewed.

\section{References}

1. Rastinehad AR, Andonian $S$, Smith AD, et al. Management of hemorrhagic complications associated with percutaneous nephrolithotomy. J Endourol 2009;23:1763-67. https://doi.org/10.1089/ end.2009.1548

2. Alsaikhan $B$, Andonian $S$. Shockwave lithotripsy in patients requiring anticoagulation or antiplatelet agents. Can Urol Assoc J 2011;5:53-7. hittps://doi.org/10.5489/cuaj.566

3. Razvi H, Fuller A, Nott L, et al. Risk factors for perinephric hematoma formation after shockwave lithotripsy: A matched case-control analysis. J Endourol 2012;26:1478-82. ht1ps://doi.org/10.1089/ end.2012.0261

4. Silberstein J, Lakin CM, P JK. Shockwave lithotripsy and renal hemorrhage. Rev Urol 2008;10:236-41.

5. Freund JB, Colonius T, Evan AP. A cumulative shear mechanism for tissue damage initiation in shockwave lithotripsy. Ultrasound Med Biol 2007;33:1495-503. https://doi.org/10.1016/i.utrasmedbio.2007.03.001

Correspondence: Dr. Sero Andonian, Division of Urology, Department of Surgery, McGill University Health Centre, Montreal, QC, Canada; sero.andonian@muhc.mcgill.ca

See Figure 1 on next page. 


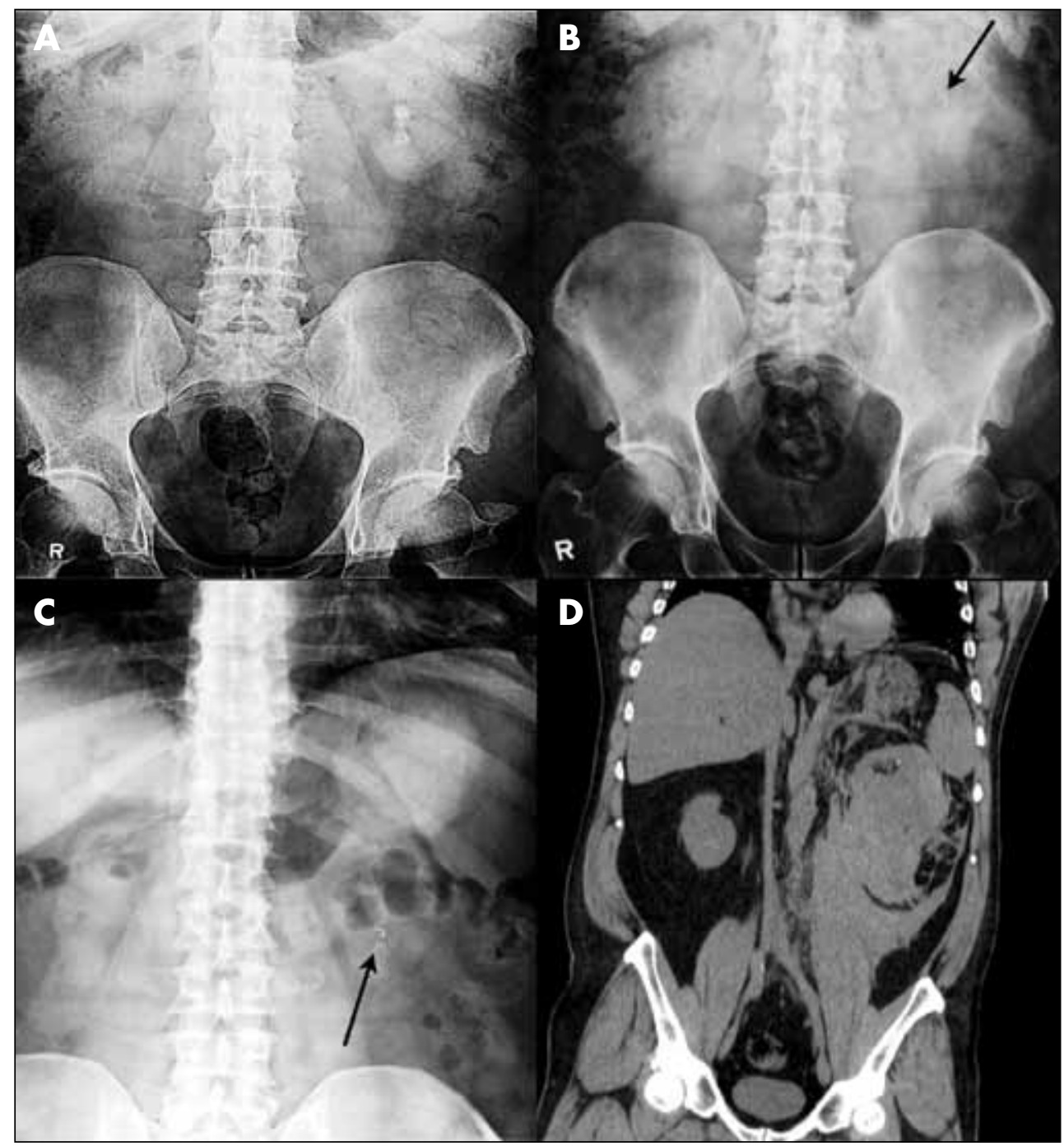

Fig. 1. (A) Pre-percutaneous nephrolithotomy of kidney-ureter-bladder (PCNL KUB) demonstrating left lower pole partial staghorn stone; $(\boldsymbol{B})$ post-PCNL KUB demonstrating stone-free status and presence of embolization coil (arrow); (C) pre-shockwave lithotripsy (SWL) KUB demonstrating $10 \times 6 \mathrm{~mm}$ lower pole stone (arrow) caudal to previous embolization coil; and (D) coronal computed tomography image demonstrating the peri-renal hematoma post-SWL. 